\title{
Implementasi Constraint CHECK dalam Aspek Kebenaran pada Basis Data di Aplikasi LaundryPOS
}

\author{
Implementation of CHECK Constraint in Correctness Aspects of \\ LaundryPOS's Database Application \\ Firstyani Imannisa Rahma1, Tinuk Agustin ${ }^{2}$, \\ Ronaldus Morgan James ${ }^{3}$, Ema Utami ${ }^{4}$ \\ 1,2,3,4 Magister Teknik Informatika, Universitas Amikom Yogyakarta \\ E-mail: "1 firstyani.rahma@students.amikom.ac.id, ${ }^{2}$ gusti.north@gmail.com, \\ 3ronaldus.1188@students.amikom.ac.id, ${ }^{4}$ emma@nrar.net
}

\begin{abstract}
Abstrak
Komponen penting yang dibutuhkan dalam sistem informasi atau perangkat lunak adalah basis data. Basis data membantu perangkat lunak dalam mengolah data yang datang dari input yang masuk ke dalam sistem. Untuk menjaga integritas dan keamanan data, programmer wajib memberikan fitur validasi data pada input. Validasi data dapat dilakukan dengan membuat batasan di tingkat aplikasi maupun di tingkat basis data. Sangat penting melakukan validasi data tingkat basis data tidak hanya pada tingkat pemrograman saja. LaundryPOS adalah aplikasi karis berbasis mobile yang diperuntukkan untuk usaha laundry. Penelitian ini akan melakukan analisis keuntungan dari CHECK constraint di database pada aplikasi LaundryPOS dalam aspek kebenaran data. Pengujian dilakukan dengan menggunakan query dan kendala. Hasil dari pengujian ini membuktikan bahwa constraint CHECK mampu menjaga aspek kebenaran pada basis data aplikasi LaundryPOS dengan menyaring data input yang tidak sesuai dengan format yang ditentukan.
\end{abstract}

Kata Kunci-CHECK constraint, integritas data, validasi data, aspek kebenaran data, MySQL

\begin{abstract}
An importantcomponents in the information system or software is database. The database helps the software process data that comes from the input that enters the system. To maintain data integrity and security, programmers must provide data validation features on the input. Data validation can be done by creating constraints at the application level or at the database level. It is very important to do database level data validation not only at the programming level. LaundryPOS is a mobile-based cashier application intended for laundry businesses. This study will analyze the benefits of CHECK constraints in the database on the LaundryPOS in terms of data correctness. Tests carried out using the query and constraints. The results of this test demonstrate that CHECK constraint is able to maintain the Correctness Aspects of the LaundryPOS database by filtering input data that does not match the specified format.
\end{abstract}

Keywords—CHECK constraints, data integrity, data validation, aspek kebenaran data, MySQL

\section{PENDAHULUAN}

Basis data adalah kumpulan dari data yang tersimpan dan saling terkait satu dengan lainnya untuk melayani kebutuhan banyak pengguna [1]. Penyimpanan data dengan basis data dianggap lebih baik daripada penyimpanan data dengan file karena penyimpanan yang lebih besar, integrasi data yang membuat akses data semakin mudah dan redundansi data yang lebih rendah. 
Salah satu peran penting basis data dalam sebuah sistem informasi atau aplikasi perangkat lunak adalah sebagai sumber informasi yang mampu memenuhi kebutuhan pengguna [2].

Sejak data relasional mendominasi software bisnis, perkembangan perancangan basis data mengalami kemajuan yang sangat pesat [3]. Banyak peneliti yang menjelaskan tentang proses perbaikan basis data untuk menjaga kualitas data [4] dan fokus pada kendala integritas [5]. Sayangnya, masih sedikit peneliti yang membahas lebih dalam tentang penggunaan constraint untuk mengendalikan data yang masuk ke dalam sistem [6][7].

Constraint dapat digunakan pada semua RDBMS seperti pada MySQL, MYSQL SERVER, ORACLE, PostGreSQL. Penerapan constraint dalam tabel pada basis data dapat menjamin konsistensi dan integritas data karena data yang dapat masuk ke dalam tabel hanya data yang sesuai dengan batasan yang telah ditentukan [8]. Salah satu constraint yang dipakai dalam basis data adalah constraint CHECK.

Penelitian ini bertujuan untuk mengetahui pentingnya sebuah CHECK constraint dalam sebuah susunan basis data dan implementasinya khususnya pada aspek kebenaran data dengan menggunakan database dari aplikasi Laundry POS sebagai studi kasus permasalahan. Pengujian dilakukan dengan melakukan pengecekan query dan constraint. Penelitian ini diharapkan mampu menjaga aspek kebenaran data di dalam basis data dengan membatasi masuknya data input yang tidak sesuai dengan format yang ditetapkan.

\section{METODE PENELITIAN}

\subsection{Tahap Review}

Penelitian ini dilakukan dengan tahapan-tahapan yang terdiri dari identifikasi masalah, tinjauan literatur, pengumpulan data dan analisis operasi query di dalam tabel sebelum dan sesudah diberi CHECK constraint dan pemberian rekomendasi untuk database. Alur penelitian dapat dilihat pada Gambar 1.

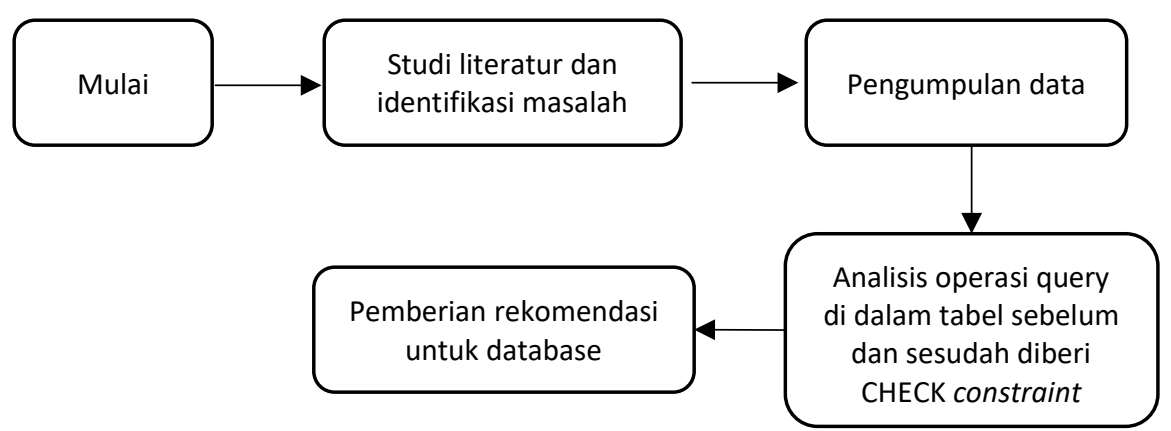

Gambar 1. Alur Penelitian

\subsection{Tinjauan Literatur}

Penelitian oleh Raharjo membahas tentang penggunaan constraint CHECK untuk menyaring data yang masuk agar sesuai dengan data yang dibutuhkan [6]. Sementara itu, Utami melakukan penelitian tentang penggunaan constrain CHECK untuk membatasi masuknya data tanggal lahir, jenis kelamin, dan kode pelajar agar data tersebut menjadi valid [7]. Kesimpulan dari kedua penelitian ini adalah constraint CHECK dapat memudahkan proses validasi data yang dibuktikan dengan proses input 1000 data yang lebih cepat 1,2 hingga 5,3 milidetik dari pada tabel yang tidak memiliki constraint CHECK.

Selanjutnya, constraint CHECK juga digunakan di pengujian dalam perancangan database pada sistem asessmen dan pemetaan hasil asessment berbasis tag sebagai pembantu penyusunan strategi pembelajaran. [9] Constraint CHECK digunakan untuk menguji kualitas database fisik yang telah dirancang sebelumnya. Pengujian contraint dilakukan dengan 
memasukkan query insert data pada setiap tabel di dalam database. Kelemahan dari penelitian ini adalah belum menjelaskan fokus aspek kualitas yang digunakan dalam pengujian Constraint CHECK dan hanya menggunakan query insert untuk mencari kesalahan dalam perancangan basis data.

\subsection{Pengumpulan data}

Proses pengumpulan data dilakukan dengan mengambil beberapa tabel dari skema database dari aplikasi mobile LaundryPOS sebagai sampel dari penelitian ini.

\subsection{Analisis data}

Pada proses analisis data query CHECK constraint ditambahkan ke dalam sebuah kolom di dalam tabel. Setelah penambahan constrain maka dilakukan pemetakan relasi tabel untuk mendapatkan rekomendasi basis data.

\section{HASIL DAN PEMBAHASAN}

Menurut Gordon B. Davis salah satu bagian penting dalam Sistem Informasi adalah masukan (input), yaitu berupa data yang akan disimpan sebagai basis data [10]. Kriteria perancangan basis data yang diperlukan untuk membuat database yang baik, antara lain 1) Setiap struktur tabel harus dibuat lebih efisien dan sistematis; 2) Penyimpanan data harus dibuat efisien; 3) Ukuran tabel harus dibuat sekecil mungkin untuk mempercepat operasi di basis data; 4) Mengoptimalkan redundansi untuk meningkatkan integritas data dan meminimalisir upaya penyebaran perubahan data dari satu tabel terkait ke tabel lainnya (catatan: dalam database relasional, redundansi data tidak dapat dihindari); 5) Ambiguitas data di semua tabel harus dihindari [11]. Constraint adalah aturan dalam basis data yang tidak boleh dilanggar karena berkaitan dengan kebenaran dan konsistensi data yang menghasilkan integritas basis data [12].

Constraint dalam database merupakan batasan nilai yang dapat memastikan hanya data yang sesuai dengan constraint saja yang dapat di input kan dalam tabel. Fungsi utama dari penerapan constraint adalah untuk menjamin integritas dan konsistensi data dalam tabel [13].

Constraint CHECK digunakan untuk meminimalkan redudansi dan meningkatkan integritas data [14]. Penelitian pada aplikasi Laundry POS ini bertujuan untuk membuktikan pentingnya penerapan constraint CHECK sebagai validasi server pada proses insert dan update data. Aplikasi Laundry POS sendiri terdiri dari 34 tabel, akan tetapi di sini penulis hanya mengambil 2 tabel saja yang akan digunakan sebagai contoh untuk dilakukan analisis terkait pentingnya penerapan constraint CHECK yaitu tabel admin dan tabel dompet.

Tabel admin sendiri terdapat 1 kolom yaitu email yang memiliki atribut varchar dengan panjang 100 karakter dengan constraint tidak boleh kosong dan bersifat unique. Permasalahan pada kolom ini adalah format data masukan email ini dapat berupa string biasa tanpa adanya pencegahan jika format masukan yang dimasukan bukan berupa format email karena tipe data email di basis data tidak ada. Hal ini sebenarnya dapat dicegah melalui validasi dari sisi coding interface nya, akan tetapi tidak menutup kemungkinan developer lupa untuk menambahkan validasi masukan berupa format email. Hal lain yang dapat terjadi adalah lemahnya validasi dari sisi sistem yang dapat ditembus oleh penyerang dari luar sistem, sehingga data email tetap bisa masuk ke basis data jika tidak adanya lapisan/validasi dari sisi basis data. Contoh serangan yang mungkin terjadi adalah SQL Injection di mana kode SQL dimasukkan atau ditambahkan ke parameter input aplikasi yang kemudian diteruskan ke server SQL backend untuk proses parsing dan eksekusi [15].

Permasalahan selanjutnya terdapat di tabel dompet, di mana di tabel ini terdapat kolom nominal dengan tipe data integer dan memiliki constraint tidak boleh kosong dan digunakan untuk menampung jumlah nominal top up saldo. Berdasarkan proses bisnis dari aplikasi ini, kolom saldo 
email yang tidak benar. Berdasarkan tampilan di Gambar 6, penulis dapat menyimpulkan bahwa perintah Insert dan Update nilai masukan email dengan format email yang tidak sesuai tidak dapat dilakukan lagi oleh database karena format yang dimasukkan tidak sesuai dengan yang format yang ditentukan di dalam prosedur.

\subsection{Tabel dompet}

Tabel dompet adalah tabel yang digunakan untuk menyimpan data jumlah top up saldo untuk setiap masing-masing akun pengguna aplikasi LaundryPOS. Tabel ini berelasi dengan tabel admin yang bertipe owner. Permasalahan yang terdapat di tabel ini yang terkait dengan penggunaan constraint CHECK adalah kolom nominal yang digunakan untuk menyimpan jumlah besaran top up yang bisa dimasukkan nilai angka negatif. Kolom di tabel dompet dapat dilihat di Gambar 7.

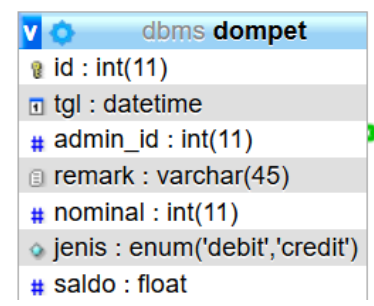

Gambar 7. tabel dompet
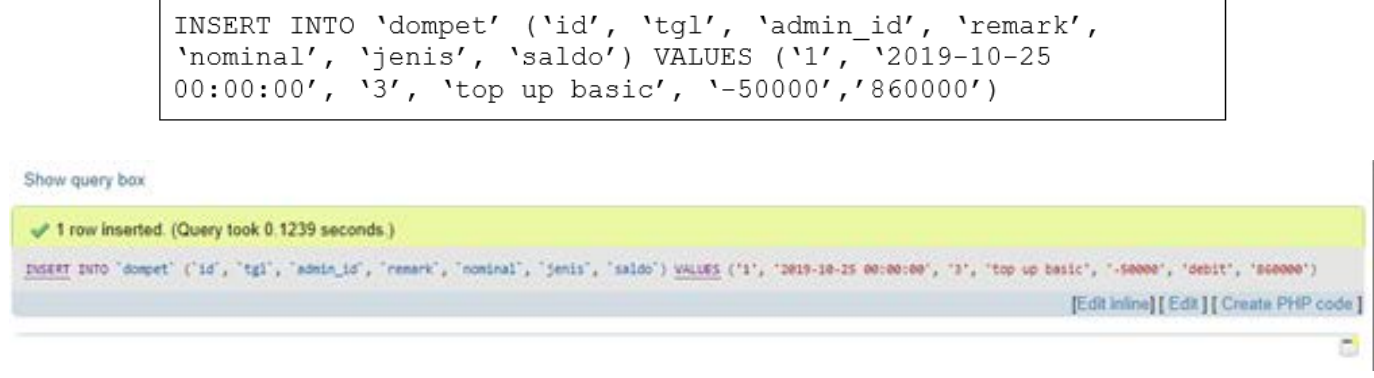

Gambar 8. insert data nominal bernilai negatif

Penulis mencoba untuk memasukkan nilai negatif pada kolom nominal bernilai -50000 dan proses insert sukses dijalankan. Berdasarkan proses bisnis, umumnya hal tersebut tidak diperbolehkan. Masuknya nominal bernilai negatif akan mengakibatkan kesalahan pada penyampaian informasi saldo yaitu setelah melakukan top up, total saldo dari owner yang melakukan top up justru malah berkurang -50000 seperti yang ditampilkan di Gambar 8.

\subsection{Penambahan Constraint CHECK}

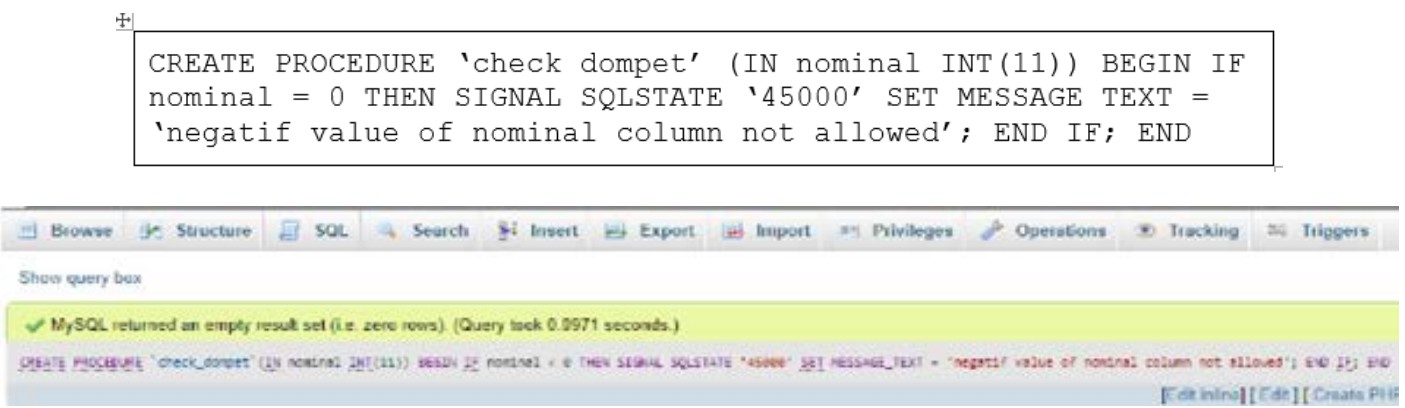

Gambar 9. prosedur validasi nilai negatif 
Citec Journal, Vol. 7, No. 2, Juli 2020

Prosedur di Gambar 9 akan memeriksa parameter masukan variabel nominal jika nilai masukan adalah nilai negatif (nilai angka dibawah 0), maka proses Insert atau Update akan diinterupsi dengan pesan error "negative value of nominal column not allowed".

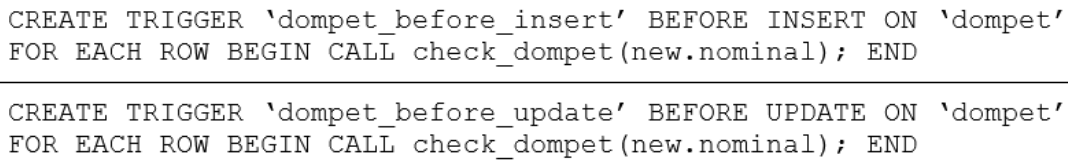

Gambar 10. Trigger before insert dan update tabel dompet

Dilakukan penambahan trigger pada proses insert dan update di tabel dompet. Trigger di Gambar 10 akan dijalankan ketika ada proses simpan saat insert atau update data di tabel dompet dengan memanggil fungsi atau prosedur untuk memvalidasi masukan nilai dari nominal yang telah dibuat.

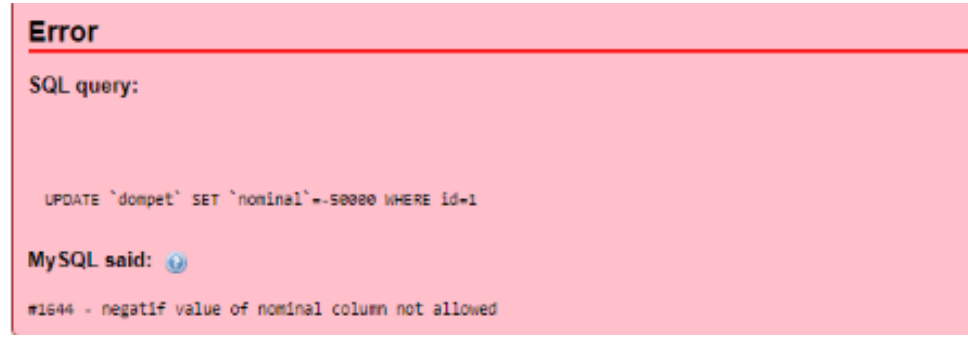

Gambar 11. Trigger before insert dan update tabel dompet

Proses update data dompet dengan masukan kolom nominal bernilai negatif (-50000) tidak berhasil dilakukan setelah ditambahkan CHECK constraint seperti yang ditampilkan dalam Gambar 11. Dengan demikian, proses bisnis atau kebenaran data nominal menjadi valid.

Tabel 1. Perbandingan hasil operasi query

\begin{tabular}{lclc}
\hline \multicolumn{2}{c}{ Sebelum Penambahan CHECK Constraint } & \multicolumn{2}{c}{ Sesudah Penambahan CHECK Constraint } \\
\hline \multicolumn{1}{c}{ Operasi Query } & Hasil & \multicolumn{1}{c}{ Operasi Query } & Hasil \\
\hline $\begin{array}{l}\text { Insert alamat email tidak sesuai } \\
\text { dengan format }\end{array}$ & sukses & $\begin{array}{l}\text { Insert alamat email tidak sesuai } \\
\text { format }\end{array}$ & gagal \\
\hline $\begin{array}{l}\text { Update alamat email tidak sesuai } \\
\text { dengan format }\end{array}$ & sukses & $\begin{array}{l}\text { Update alamat email tidak sesuai } \\
\text { format }\end{array}$ & gagal \\
\hline Insert alamat email sesuai format & sukses & Insert alamat email sesuai format & sukses \\
\hline Update alamat email sesuai format & sukses & Update alamat email sesuai format & sukses \\
\hline $\begin{array}{l}\text { Insert nominal saldo dompet bernilai } \\
\text { negatif }\end{array}$ & sukses & $\begin{array}{l}\text { Insert nominal saldo dompet bernilai } \\
\text { negatif }\end{array}$ & gagal \\
\hline $\begin{array}{l}\text { Update nominal saldo dompet } \\
\text { bernilai negatif }\end{array}$ & sukses & $\begin{array}{l}\text { Update nominal saldo dompet } \\
\text { bernilai negatif }\end{array}$ & gagal \\
\hline $\begin{array}{l}\text { Insert nominal saldo dompet bernilai } \\
\text { positif }\end{array}$ & sukses & $\begin{array}{l}\text { Insert nominal saldo dompet bernilai } \\
\text { positif }\end{array}$ & sukses \\
\hline $\begin{array}{l}\text { Update nominal saldo dompet } \\
\text { bernilai positif }\end{array}$ & sukses & $\begin{array}{l}\text { Update nominal saldo dompet } \\
\text { bernilai positif }\end{array}$ & sukses \\
\hline
\end{tabular}


Berdasarkan perbandingan hasil operasi query Insert dan Update di Tabel 1, penulis menyimpulkan bahwa dengan adanya penambahan CHECK constraint pada kolom di sebuah tabel mampu mencegah input yang tidak sesuai kebutuhan masuk ke dalam sistem. Oleh karena itu, aspek kebenaran dari setiap kolom dalam sebuah tabel dapat terpenuhi.

\section{KESIMPULAN}

Berdasarkan pada penelitian yang dilakukan, penggunaan constraint CHECK pada basis data mampu menyaring data input yang masuk ke dalam tabel agar sesuai pada format yang telah ditentukan. Dalam constraint CHECK atau trigger dan prosedur yang serupa, pengguna dapat mengatur masuknya data sesuai dengan format yang dibutuhkan, dalam kasus ini digunakan untuk mengatur dan mengecek input atau update alamat email dan nominal saldo. Setelah diberi constraint CHECK, data yang tidak sesuai dengan format yang ditentukan akan ditolak dalam sistem. Oleh karena itu, penggunaan CHECK juga mampu menjaga basis data dalam segi aspek kebenaran data.

\section{SARAN}

Untuk menindaklanjuti beberapa kekurangan pada saat analisis, ada beberapa tindakan penyempurnaan sebagai berikut:

1. Penelitian ini hanya menganalisis penggunaan CHECK constraint terhadap aspek kualitas kebenaran data, sehingga untuk penelitian berikutnya diharapkan mampu menganalisis penggunaan constraint ini terhadap aspek kualitas lainnya.

2. Penelitian berikutnya mampu mengukur waktu pengoperasian query saat tabel diberikan CHECK constraint agar dapat mengukur efisiensi pemakaian basis data.

\section{DAFTAR PUSTAKA}

[1] Teorey, T., Lightstone, S., Nadeau, T., Jagadish, H. V., 2006, Database Modeling and Design, Fourth Edition, Morgan Kaufmann Publishers, San Francisco.

[2] Raharjo, S., Sutanta, E., Utami, E., 2007, Analisis Aspek-Aspek Kualitas Schema Database (Studi Kasus pada Database Akademik ISTA Yogyakarta), Seminar Nasional Teknologi 2007, Yogyakarta, 24 November

[3] Toerey, J. T., 1999, Database Modelling \& Design, San Francisco, Third Edition, Morgan Kaufmann Publishers, San Francisco.

[4] Lubis, J. H., 2017, Analisa Performansi Query Pada Database Smell, Jurnal Manajemen dan Informatika Pelita Nusantara, Vol. 21, No.1, hal. 42-49, ST

[5] Benedikt, M., Leblay, J., Tsamoura, E., 2015, Querying with Access Patterns and Integrity Constraints, 41st International Conference on Very Large Data Bases (VLDB), Kohala Coast, 31 Agustus - 4 September

[6] Raharjo, S., 2012, Constraint Basis Data Sebagai Fondasi Yang Kuat Dalam Pengembangan Sistem Informasi. Seminar Nasional Aplikasi Sains \& Teknologi (SNAST) Periode III, Yogyakarta, 3 November

[7] Utami, E., 2014, The Advantages of Using CHECK Constraints in The Academic Database Tables, Journal of Software, No.2, Vol. 9, Hal. 382-388. 
Citec Journal, Vol. 7, No. 2, Juli 2020

[8] Arief, R., 2005, Pemrograman Basis Data dengan Transact-SQL menggunakan SQL Server, Penerbit Andi, Yogyakarta.

[9] Kurnianti, A., Angguningtyas, A., Isnanda, R. G., 2017, Perancangan Database Pada Sistem Asessmen Dan Pemetaan Hasil Asessmen Berbasis Tag Sebagai Pembantu Penyusunan Strategi Pembelajaran, Semesta Teknika, Vol. 20, No. 2, Hal. 106-115.

[10] Davis, G. B., 1984, Kerangka Dasar Sistem Informasi Manajemen, Terjemahan, PT Midas Surya Grafindo, Jakarta.

[11] Date, C. J., 1995, An Introduction to Database System, Addison-Wesley, Reading.

[12] Connoly, T., Begg, C., 2010, Database System: A Practical Approach to Design, Implementation, and Management - Fifth Edition, Pearson Education, Essex.

[13] Arief, R., 2010, Implementasi Constraint untuk Menjamin Konsistensi dan Integritas Data Dalam Database, Jurnal DASI, Vol. 11, No.2, Hal. 62-71.

[14] Yunita, S., Sholeha, E. W., Hardita, V. C., Utami, E., 2018, Database Modelling for the Expertise of Special Needs Teachers, Journal of Physics Conference Series, Vol. 1140, No. 1, Hal. 1-9.

[15] Clarke, J., 2012, SQL Injection Attacks and Defense, Second Edition, Syngress, Rockland. 